\title{
RESUMOS DE DISSERTAÇÕES E TESES
}

\author{
Resumos impressos de acordo com os originais enviados \\ pelas respectivas Coordenadorias de Pós-Graduação
}

\section{Universidade Estadual Paulista de Botucatu}

\author{
TítULO: Aspectos bioquímicos da embriogênese somática em cenoura (Daucus carota L.) \\ AUTOR: Jurema Schons \\ DATA: $\quad$ janeiro de 1995 \\ LOCAL: IB - Botucatu-SP \\ NÍVEL: Mestrado \\ BANCA EXAMINADORA: Oswaldo Galvão Brasil (orientador) - UNESP/Botucatu \\ João Domingos Rodrigues - UNESP/Botucatu \\ Ede Cereda - UNESP/Botucatu
}

\begin{abstract}
RESUMO - Calos foram obtidos a partir de segmentos de raizes de cenoura (Daucus carota $\mathrm{L}$.) em meio MS suplementado com $0,2 \mathrm{mg} / \mathrm{l}$ de 2,4-d e $0,1 \mathrm{mg} / \mathrm{l}$ de cinetina. Estes calos foram utilizados para suspensão de células as quais foram inoculadas em meio líquido contendo a mesma combinação de fitorreguladores acima descrita e mantidos sob agitação a $90 \mathrm{rpm}$, temperatura de $25 \pm 1^{\circ} \mathrm{C}$, fotoperíodo de $12 \mathrm{~h}$ e intensidade luminosa de 200 lux. Após 14 dias, as células foram transferidas para meio MS desprovido de fitorreguladores para a indução de embriogênese. A cada 4 dias foram retiradas alíquotas para as análises bioquímicas. Dois picos foram observados na atividade da nitrato redutase: no final da fase de divisão celular e no período que antecedeu à formação de torpedos, quando havia maior disponibilidade de nitrato no meio. A peroxidase apresentou oscilações nas diferentes fases, sendo que a maior atividade foi observada no período que antecedeu a formação de torpedos. Os teores de açúcares redutores aumentaram sempre que houve maior disponibilidade de sacarose no meio de cultura. Os parâmetros bioquímicos caracterizam as fases da embriogênese somática, sendo que o meio de cultura mostrou ser um elemento essencial para a atividade da perioxidase da nitrato redutase e também dos níveis de proteínas e açúcares redutores.
\end{abstract}

TÍTULO: Efeitos da refrigeração, fungicida e de alguns fitorreguladores na fisiologia pós-colheita de mamão (Carica papaya L.) cv solo

AUTOR: Regina Celi Cavestre Coneglian

DATA: $\quad$ janeiro de 1995

LOCAL: IB - Botucatu-SP

NIVEL: Doutorado

BANCA EXAMINADORA: João Domingos Rodrigues (orientador) - UNESP/Botucatu

Paulo Roberto de Camargo e Castro - ESALQ/Piracicaba/USP

José Santo Goldoni - UNESP/ Botucatu

Oswaldo Galvão Brasil - UNESP/Botucatu

José Figueiredo Pedras - UNESP/Botucatu

RESUMO - Estudou-se a ação da refrigeração, um fungicida e de alguns fitorreguladores em frutos de mamão (Carica papaya L.) pós-colheita, pertencentes ao cultivar solo, em estádio pré-climatérico, visando a manutenção de suas qualidades. A partir da data dos tratamentos, a cada 4 dias, realizaram-se amostragens aleatórias de 2 frutos para cada tratamento e após cada uma delas, os frutos foram submetidos a determinaçōes de: cor, textura, peso úmido, umidade, perda de peso, acidez, pH, carboidratos solúveis, índice refratométrico, açúcares totais e redutores, vitamina $\mathrm{C}$, beta-criptoxamina e beta-caroteno, além de 
vitamina $\mathrm{A}$ e minerais (N, P, K, Ca, Mg, Zn e B). A avaliação dos resultados mostrou que: para cor e textura a utilização da temperatura controlada foi decisiva na manutenção dos frutos (mais verdes e mais firmes por mais tempo); a utilização do fungicida foi benéfica em termos da manutenção dos níveis de açúcares redutores e vitamina $\mathrm{C}$, quando aliado ao uso dos fitorreguladores em frutos colocados a temperatura ambiente; quanto aos fitorreguladores, sua ação foi mais eficaz quando utilizados em conjunto, sobretudo quando combinados com a refrigeração, em termos de níveis mais elevados de carboidratos solúveis, vitamina $\mathrm{C}$, açúcares totais e acidez.

TÍTULO: Composição florística, perfis de concentração de $\mathrm{CO}_{2}$ e variação natural da razão isotópica ${ }^{13} \mathrm{C} /{ }^{12} \mathrm{C}$ em floresta de terra firme da Amazônia Central

AUTOR: Edelcílio Marques Barbosa

DATA: março de 1995

LOCAL: IB - Botucatu-SP

NIVEL: Doutorado

BANCA EXAMINADORA: Dinival Martins (orientador) - UNESP/Botucatu

João Domingos Rodrigues - UNESP/Botucatu

Carlos Ducatti - UNESP/Botucatu

Paulo Rodolfo Leopoldo - UNESP/Botucatu

Luiz Antonio Martinelli - USP/CENA/Piracicaba

RESUMO - Foi analisada a composição florística em um hectare de floresta de terra firme localizado na Reserva Florestal Ducke, Manaus-AM, onde verificou-se 46 famílias botânicas distribuídas em 126 gêneros e 179 espécies, representadas por 676 indivíduos. Estabeleceram-se diferentes alturas no interior da floresta para as determinaçōes da concentração de gás carbônico e da variação natural da razão isotópica ${ }^{13} \mathrm{C} /{ }^{12} \mathrm{C}$ no ar atmosférico. Semelhante determinação foi também feita para a variação natural da razão isotópica ${ }^{13} \mathrm{C} /{ }^{12} \mathrm{C}$ contidos na matéria orgânica foliar em diferentes espécies vegetais. A variação horária da concentração de $\mathrm{CO}_{2}$ do ar atmosférico na floresta mostrou uma tendência a flutuação durante o dia, com valores máximos registrados às 6 horas da manhā, decrescendo paulatinamente até as 14 horas. Isso ocorre pois durante à noite, $\mathrm{o} \mathrm{CO}_{2}$ acumula entre as plantas e, principalmente, junto à superfície do solo. Os valores da $\mathrm{S} 13$ (variação da razão isotópica ${ }^{13} \mathrm{C} /{ }^{12} \mathrm{C}$ ) teve um comportamento inverso ao da concentração com $\mathrm{CO}_{2}$, com valores mínimos observados às 6 horas da manhã e máximas às 14 horas. A estratificação dos valores do S13C para matéria orgânica foliar foram sempre maiores no nível superior das copas das árvores que nos níveis inferiores. Finalmente, demonstrou-se que a composição isotópica das amostras do "litter" possui sempre valores da S13 similares ao das folhas dos níveis superiores.

TÍTULO: Anatomia e fitoquímica foliar de Tetradenia riparia (Hochst) Codd.

AUTOR: Flávia Cristina Sossae

DATA: junho de 1995

LOCAL: IB - Botucatu-SP

NÍVEL: Mestrado

BANCA EXAMINADORA: Arildo Bueno Rocha (orientador) - UNESP/Arararaquara

José Jorge Neto - UNESP/Botucatu

João Domingos Rodrigues - UNESP/Botucatu

RESUMO - Os estudos anatômicos de folhas adultas de Tetradenia riparia demonstraram a presença de epiderme unisseriada coberta por cutícula, com estômatos diacíticos na face abaxial e adaxial do limbo. As folhas são portadoras de tricomas glandulares. O sistema vascular é colateral. O mesofilo é heterogêneo em folha adulta. Foi constatada a presença de hidatódios em primórdios foliares. Identificaram-se dois tipos de 
tricomas secretores, peltados e capitados. Os tricomas peltados foram diferenciados em 2 tipos e os capitados em 5 . O conteúdo dos tricomas foi analisado nos testes microquímicos com corantes específicos para a detecção de lipídios, mucilagem, proteínas totais e fenóis em todos os tipos de tricomas. Foi verificada a presença de mucilagem em alguns tricomas capitados. Verificou-se a presença de lipídios, fenóis e proteínas totais. Não foi verificada a presença de alcalóides, antracenodidos, flavonóides, óleo essencial, saponinas e taninos. Foram evidenciados a presença de óleo essencial, mucilagem e taninos nas folhas de $T$. riparia.

TÍTULO: Efeito de giberelina e citocinina no desenvolvimento de plantas de alface (Lactuca sativa L.) cv. Elisa em cultivo hidropônico

AUTOR: Heroy Ótilo Mehl

DATA: junho de 1995

LOCAL: IB - Botucatu-SP

NÍVEL: $\quad$ Mestrado

BANCA EXAMINADORA: João Domingos Rodrigues (orientador) - UNESP/Botucatu

José Antonio Proença Vieira de Moraes - UFSCAR

José Figueiredo Pedras - UNESP/Botucatu

RESUMO - Estudou-se o efeito de giberelina e citocinina no desenvolvimento de alface (Lactuca sativa) cv. Elisa, em fase vegetativa, através de avaliação de medidas biométricas, da análise de crescimento e da determinação de proteínas solúveis e clorofila. Delinearam-se 4 tratamentos, a saber: T1 (testemunha), T2 (ga3-15 ppm), T3 (citocinina - 10 ppm), T4 (ga 3-15 ppm + citocinima - 10 ppm). O experimento foi instalado em cultivo hidropônico ( $\mathrm{mft}$ ) em casa de vegetação. O delineamento estatístico foi de parcelas subdivididas, considerando 5 coletas, aos $30,37,44,51$ e 58 dias após a germinação, com 3 repetições, contendo 12 plantas. A análise dos resultados obtidos permitiu concluir que, nas condições estudadas, as plantas alcançaram melhor desenvolvimento quando submetidas ao tratamento com citocinina, aplicada por 2 vezes na concentração de 10 ppm, aos 30 e 40 dias após a germinação.

TÍTULO: Estudo de aspectos da germinação e dormência de semestes de Grevillea robusta A. Cunn. AUTOR: Terezinha Catarina Heck Schallenberger

DATA: novembro de 1995

LOCAL: IB - Botucatu-SP

NÍVEL: Mestrado

BANCA EXAMINADORA: Maria Elena A. Delachiave (orientadora) - UNESP/Botucatu

José Figueiredo Pedras - UNESP/Botucatu

Joảo Nakagawa - UNESP/Botucatu

RESUMO - Foram instalados experimentos com sementes de 4 plantas de Grevillea robusta para estudar a variação do poder germinativo e tratamentos pré-germinativos para uniformizar a germinação. No experimento I as sementes receberam os seguintes tratamentos: $\mathrm{T} 1=$ testemunha; $\mathrm{T} 2=\mathrm{imers} a \mathrm{a}^{\mathrm{em}} \mathrm{KNO}_{3}$ a $0,2 \%$ por 24 hs; $\mathrm{T} 3=$ substrato umedecido com solução de $\mathrm{KNO}_{3}$ a $0,2 \%$; T4=pré-resfriamento $\mathrm{a} \pm 5^{\circ} \mathrm{C}$ por 7 dias; T5=imersão em água parada por $24 \mathrm{~h}$; T6=imersão em água parada por $48 \mathrm{~h}$; T7=lavagem em água corrente por $24 \mathrm{~h}$ e T8=lavagem em água corrente por $48 \mathrm{~h}$. As sementes foram colocadas para germinar $\mathrm{a} \pm 30^{\circ} \mathrm{C}$, fotoperíodo de $9 \mathrm{~h}$ luz e $15 \mathrm{~h}$ escuro, contando-se as sementes germinadas deterioradas e firmes por 28 dias. Simultaneamente, instalou-se o experimento II com sementes de 2 plantas (b e c) que receberam os mesmos tratamentos (exceto o T3), sendo que foram colocados para germinar em 4 substratos (solo, areia, drenagem, cinza) fazendo contagens também por 28 dias. Nos 2 primeiros experimentos ocorreram diferenças significativas na porcentagem média da germinação entre plantas, tratamentos e substratos. A planta b apresentou as maiores porcentagens de germinaçẫo, sendo que T2 e T4 foram os 
melhores tratamentos. As sementes da planta c mostraram altas porcentagens de sementes deterioradas e a planta d apresentou altas porcentagens de sementes firmes.

TÍTULO: $\quad$ Atividade de hidrolases em sementes de soja (Glycine max L. Merril) durante a germinação sob diferentes concentrações de alumínio e potenciais hídricos

AUTOR: Ana Catarina Catâneo.

DATA: novembro de 1995

LOCAL: IB - Botucatu-SP

NÍVEL: Doutorado

BANCA EXAMINADORA: Celso Rossi (orientador) - UNESP/Botucatu

Otto Jesu Crocomo - ESALQ/Piracicaba/USP

Luiz Antonio Gallo - ESALQ/Piracicaba/USP

Maria Elena Ap. Delachiave - UNESP/Botucatu

Wanderley José de Melo - UNESP/Botucatu

RESUMO - Sementes de dois cultivares de soja (BR-04, tolerante à seca; BR-16, susceptível à seca) foram colocadas para germinar em diferentes potenciais hídricos induzidos pelo manitol $(-0,5 ;-1,0 ;-1,5$ mpa) e/ou concentrações de sulfato de alumínio $\left(1 ; 5 ; 10 \mathrm{mmol}^{\mathrm{l}^{-1}}\right)$. Foram determinadas as atividades de amilase, protease e urease nos eixos embrionários e cotilédones das sementes em várias fases de germinação $(6 ; 18 ; 24 ; 48$ e $60 \mathrm{~h}$ após o início do experimento) e a porcentagem de germinação às $60 \mathrm{~h} . \mathrm{A}$ porcentagem de germinação do cultivar BR-04 foi maior que o do cultivar BR-16, em todos os tratamentos. $\mathrm{O}$ aumento da deficiência hídrica causou decréscimo na porcentagem de germinação dos dois cultivares, mas o aumento da concentração de alumínio não provocou este efeito. Os cultivares BR-04 e BR-16 apresentaram comportamento diferenciado nos períodos de 18 e $24 \mathrm{~h}$ de germinação, em relação às atividades de amilase, protease e urease. A enzima que mais contribui para esta diferenciação foi a urease.

TÍTULO: Levantamento de plantas medicinais na Reserva Extrativista "Chico Mendes"- Acre

AUTOR: $\quad$ Lin Chau Ming

DATA: dezembro de 1995

LOCAL: IB - Botucatu-SP

NÍVEL: Doutorado

BANCA EXAMINADORA: Ayrton Amaral Júnior (orientador) - UNESP/Botucatu

Elaine Elisabetsky - UFRGS

Rachel Trajber

Manoel Gabino C. Churata-Masca - UNESP/Botucatu

Douglas Charles Dale - NYBG

RESUMO - O trabalho foi realizado em seis viagens, entre novembro/91 e fevereiro/95, em 20 seringais da Reserva, nos municípios de Xapuri e Brasiléia, tendo sido estrevistadas 53 pessoas, com 161 espécies de 62 famílias. Obteve-se também dados referentes aos entrevistados, das plantas, da situação social e cultural das comunidades, além das principais doenças e/ou sintomas. $\mathrm{O}$ trabalho teve ampla discussão e posterior apoio do Conselho Nacional dos Seringueiros e dos Sindicatos de Trabalhadores Rurais de Brasiléia e Xapuri, além do apoio do Parque Zoobotânico da Universidade Federal do Acre e Jardim Botânico de New York.

TÍTULO: Efeito de diferentes substratos no cultivo de crisântemo (Dendranthema grandiflorum (Ramat) Kitam.) em vaso

AUTOR: Denise Laschi 
DATA: fevereiro de 1996

LOCAL: IB - Botucatu-SP

NÍVEL: Mestrado

BANCA EXAMINADORA: Selma Dzimidas Rodrigues (orientadora) - UNESP/Botucatu

Maria Alice de L. Bueno Souza - UNESP/Botucatu

José Figueiredo Pedras - UNESP/Botucatu

RESUMO - O objetivo do presente trabalho, instalado em casa de vegetação da Cooperativa Agropecuária Holambra-SP, de 08/11/93 a 17/02/94, foi testar diferentes materiais alternativos, combinados ou não, para obtenção de um substrato, a fim de produzir o crisântemo em vaso. Estes substratos continham: bagaço de cana moído, vermiculita, palha de arroz carbonizada, carvão vegetal moído e esterco de curral, todos adicionados à areia. Assim, foram obtidos 25 tratamentos, que foram comparados a um padrâo (solo mais pó de xaxim na proporção 3:1). Após o florescimento foi medido: peso seco e fresco de raízes, folhas, inflorescências e caule, volume radicular, comprimento da raiz principal, comprimento da planta, número e diâmetro de inflorescências. $\mathrm{O}$ bagaço de cana foi o componente que produziu plantas com menor valor comercial e pode ser utilizado quando adicionado a outros componentes. O sistema radicular teve melhor desenvolvimento em vermiculita (volume) e em casca de arroz (comprimento). Todas as medidas de parte aérea tiveram melhor resposta com o uso do esterco e seu efeito é aumentado com a adição de carvão.

TÍTULO: Anatomia quantitativa e composição bromatológica de folha e caule de três espécies de Cynodon Rich.

AUTOR: Marilia Contin Ventrella

DATA: fevereiro de 1996

LOCAL: IB - Botucatu-SP

NIVEL: $\quad$ Mestrado

BANCA EXAMINADORA: Roberto Antonio Rodella (orientador) - UNESP/Botucatu

Ciniro Costa - UNESP/Botucatu

Beatriz Apezzatto da Glória - ESALQ/USP/Piracicaba

RESUMO - O presente trabalho tem por objetivo estudar, quantitativamente, a anatomia da folha e do caule de Cynodon dactylon (L), Cynodon plectostachyus (Schum.) Pilger e Cynodon nlemfuensis Schum., em duas épocas distintas, inverno e verão, procurando estabelecer relaçōes com sua composição bromatológica e digestibilidade in vitro, visando fornecer subsídios para o melhor conhecimento dessas espécies como forrageiras. Utilizou-se o delineamento inteiramento casualizado em parcelas subdivididas, considerando-se como tratamento principal as três espécies de Cynodon e como tratamento secundário as épocas de avaliação. A análise anatômica quantitativa de folha e caule sugere que $C$. dactylon seja mais favorável ao consumo, portanto, de maior digestibilidade potencial, enquanto $C$. nlemfuensis mostra menor digestibilidade potencial e $C$. plectostachyus apresenta-se em situação intermediária. Houve diferenças no comportamento das espécies de acordo com a época de avaliação. Durante o inverno, todas as espécies mostraram uma composição bromatológica mais favorável ao consumo animal.

TíTULO: Efeitos fisiológicos de chlormequat e de giberelinas $\left(\mathrm{GA}_{4+7}\right)$ mais citocinina sobre o primeiro ciclo do desenvolvimento da mandioca (Manihot esculenta Crantz cv. IAC 576-70)

AUTOR: Ana Angélica Henrique Fernandes

DATA: abril de 1996

LOCAL: IB - Botucatu-SP

NÍVEL: Doutorado

BANCA EXAMINADORA: João Domingos Rodrigues (orientador) - UNESP/Botucatu

Paulo Roberto Camargo Castro - ESALQ/USP/Piracicaba 
José Antonio Proença Vieira de Moraes - UFSCar

Carmen Sívia Fernandes Boaro Martins - UNESP/Botucatu

Silvio José Bicudo - UNESP/Botucatu

RESUMO - O presente estudo teve como finalidade avaliar o comportamento de mandioca (Manihot esculenta cv IAC 576-70), durante o primeiro ciclo vegetativo, submetida à chlormequat e giberelinas mais citocinina. O experimento foi conduzido em campo, na Fazenda Experimental de São Manuel UNESP. Foram utilizados 12 tratamentos correspondendo a diferentes concentraçōes, formas e épocas de aplicações dos produtos comerciais cycocel e promalim. Cada tratamento contou com 3 repetições, cada qual contendo 2 plantas, as quais foram utilizadas na forma de médias para análise de crescimento e avaliação do ácido cianídrico, amido e fibras das raizes tuberosas. Foram realizadas nove coletas com intervalo de 14 dias entre si. Foi utilizado delineamento experimental em blocos ao acaso. As plantas tratadas com giberelinas e citocinina apresentaram maiores valores para altura, número de folhas, matéria seca de caule e de folhas. Quanto aos dados de produção, o número e matéria fresca de raízes foram superiores nas plantas que receberam chlormequat, comparadas àquelas que receberam giberelinas mais citocinina. Os reguladores aumentaram o teor de ácido cianídrico e diminuiram o conteúdo de fibras. O conteúdo de amido diminuiu nas plantas tratadas com chlormequat. A razão de área foliar e a razão de massa foliar declinaram nas plantas tratadas com chlormequat. A taxa assimilatória líquida e o índice de área foliar foram inversamente proporcionais.

TíTULO: Efeitos das interações entre auxinas, ácido bórico e época de coleta no enraizamento de estacas herbáceas de alecrim (Rosmarinus officinalis L.)

AUTOR: Celi de Paula Silva

DATA: $\quad$ junho de 1996

LOCAL: IB - Botucatu-SP

NÍVEL: $\quad$ Mestrado

BANCA EXAMINADORA: José Figueiredo Pedras (orientador) - UNESP/Botucatu

João Domingos Rodrigues - UNESP/Botucatu

Ede Cereda - UNESP/Botucatu

RESUMO - O presente trabalho teve por objetivo verificar os efeitos de auxinas sintéticas, do ácido bórico e da época, sobre o enraizamento de estacas herbáceas de alecrim (Rosmarinus officinalis). O experimento foi conduzido em câmara de nebulização no Departamento de Botânica do Instituto de Biociências, da Universidade Estadual Paulista - UNESP - Botucatu-SP. Durante os anos de 1993 e 1994 foram utilizadas estacas herbáceas, com aproximadamente $10 \mathrm{~cm}$ de comprimento, 3 gemas e com folhas na metade apical. As bases das estacas foram imersas em soluções contendo auxinas ou ácido bórico a 150 $\mu \mathrm{g} / \mathrm{ml}$ por um período de $12 \mathrm{~h}$, resultando das combinaçōes entre NAA (ácido naftalenoacético) e IBA (ácido indolbutírico) e/ou ácido bórico. Realizou-se as seguintes observações: número de estacas enraizadas, número de raízes/estaca, peso de matéria fresca de raízes, peso de matéria seca de raízes e número de estacas mortas. A melhor época de coleta foi o final do inverno, com efeito positivo do ácido bórico sobre o número de estacas enraizadas.

TÍTULO: Variaçâo nos teores de prolina e poliaminas em cultivares de trigo (Triticum aestivum L.) submetidos a déficits hídricos

AUTOR: Terezinha de Fátima Fumis

DATA: julho de 1996

LOCAL: IB - Botucatu-SP

NÍVEL: Doutorado 
BANCA EXAMINADORA: José Figueiredo Pedras (orientador) - UNESP/Botucatu

João Domingos Rodrigues - UNESP/Botucatu

Antonio Evaldo Klar - UNESP/Botucatu

José Antonio Proença Vieira de Moraes - UFSCar

Luiz Antonio Gallo - ESALQ/USP/Piracicaba

RESUMO - Objetivando avaliar os efeitos de diferentes níveis de umidade do solo na cultura do trigo (Triticum aestivum L.) em Anahuac e IAC-24, nos níves de prolina e poliaminas, bem como em alguns parâmetros fisiológicos e de produção, conduziu-se este experimento em túnel de vegetação. O delineamento experimental utilizado foi um fatorial inteiramente casualizado, com 2 cultivares, 3 tratamentos de correntes da umidade do solo ( 1,6 a $6 \% ; 1,6$ a $11 \%$ e $16 \%$ ), 4 coletas e 3 repetiçōes, num total de 45 vasos de plástico para cada cultivar, contendo $10 \mathrm{~kg}$ de terra, textura arenosa. As medidas bioquímicas e fisiológicas avaliadas nos estádios fenológicos de perfilhamento, emborrachamento, florescimento e enchimento dos grãos e as médias biométricas foram realizadas no período vegetativo, com intervalos de 14 dias, perfazendo 5 coletas. Os resultados obtidos evidenciaram que o déficit hídrico induziu ao menor (T.R.A.) e ao maior índice refratométrico (I.R.) e aumento nos níveis de prolina e poliaminas, destacandose entre estas a putrescina, como aquela de nível mais elevado. Foi verificado também diminuição na altura, área foliar, matéria seca e nos componentes de produção. $\mathrm{O}$ cv. Anahuac apresentou menores valores nos componentes bioquímicos e na produção de grãos, quando comparado ao IAC-24. O Anahuac também apresentou, em todos os tratamentos, menores valores na altura, área foliar e matéria seca.

TÍTULO: Composição florística e estrutura da comunidade de plantas daninhas em cultura de Eucalyptus grandis W. Hill ex. Maiden.

AUTOR: João Carlos Nordi

DATA: julho de 1996

LOCAL: IB - Botucatu-SP

NIVEL: $\quad$ Mestrado

BANCA EXAMINADORA: Rita de Cássia S.M. Rodella (orientadora) - UNESP/Botucatu

Flávio Henrique M. Schlittler - UNESP/Rio Claro

Edivaldo Domingues Velini - UNESP/Botucatu

RESUMO - Foi realizado o levantamento da composição florística e da estrutura fitossociológica da vegetação de subosque, de uma plantação de Eucalyptus grandis, localizada na Fazenda Santa Terezinha, de propriedade da Eucatex Florestal Ltda, situada no município de Bofete, Estado de São Paulo, Brasil. A área total dos três talhōes estimados abrangeu $5928 \mathrm{~m}^{2}$. O clima da região, segundo Koeppen, e mesotérmico de inverno seco, sendo julho o mês seco e frio, janeiro o mês quente e úmido. O tipo de solo da região é latossolo vermelho amarelo, textura média. O método utilizado para o estudo da vegetação foi o de parcelas múltiplas ou método quadrado. Foram estudados três talhões de eucalipto em idades diferentes de crescimento, apresentando 3 anos, 2 anos e 6 meses, respectivamente. Foi encontrado o início da formação de um estrato arbustivo no talhão mais velho, com altura de $1,5 \mathrm{~m}$. A estimativa de ocorrência para o talhão mais velho foi de $1,53 \mathrm{ind} / \mathrm{m}^{2}$, para o talhão intermediário de $1,11 \mathrm{ind} / \mathrm{m}^{2}$ e para o talhão mais jovem de $2,73 \mathrm{ind} / \mathrm{m}^{2}$. As espécies mais importantes nos talhões velho, intermediário e jovem foram, respectivamente, Melinis minutiflora, Macfadyena unguis-cati e Peschiera fuchisiaefolia. Observou-se que as diferenças mais marcantes entre os subosques dos diferentes talhões foram de ordem quantitativa, pois houve altos índices de similaridade na sua composição.

TíTULO: Composição florística e estrutura fitossociológica de uma área de cerrado no Município de Agudos - SP

AUTOR: Alzira Politi Bertoncini 
DATA: setembro de 1996

LOCAL: IB - Botucatu-SP

NÍVEL: Mestrado

BANCA EXAMINADORA: Osmar Cavassan (orientador) - UNESP/Bauru

Ricardo Ribeiro Rodrigues - ESALQ/USP/Piracicaba

Rita de Cássia S. M. Rodella - UNESP/Botucatu

RESUMO - Foram realizados estudos florístico e fitossociológico em uma área de cerrado, pertencente à Cia. Cervejaria Brahma, situada no km 317 da via Mal. Rondon, no município de Agudos-SP, localizada entre as coordenadas $22^{\circ}$ e $23^{\circ} \mathrm{S}$ e $49^{\circ} 30^{\prime}$ e $48^{\circ} 50 \mathrm{~W}$ a $550 \mathrm{~m}$ de altitude. Para o levantamento fitossociológico foram instaladas 15 parcelas de $150 \mathrm{~m}^{2}$, onde foram amostrados todos os indivíduos lenhosos com diâmetro basal mínimo de $3 \mathrm{~cm}$. Na composição florística foram consideradas todas as espécies encontradas, independentemente de obedecerem aos critérios de amostragem fitossociológica. O solo e o clima foram também caracterizados. Foram amostrados fitossociologicamente 1621 indivíduos (sendo 108 mortos) pertencentes a 71 espécies, 46 gêneros e 31 familias. Vochysia tucanorum foi a espécie mais importante, seguida por Rapanea umbellata e Ouratea spectabilis. Quanto às famílias, os maiores valores de IVI foram obtidos por Vochysiaceae. Myrsinaceae e Ochnaceae. Constatou-se que nestes casos a presença de uma única espécie foi suficiente para determinar o grau de importância de sua família. Na comunidade foram encontradas 212 espécies, distribuídas em 139 gêneros e 60 famílias, pertencentes aos estratos herbáceo-subarbustivo e arbustivo-arbóreo, bem como epífitas e lianas. A maior riqueza em espécies foi registrada para a família Asteraceae e para as subclasses Rosidae e Asteridae (florística) e para Myrtaceae, Rosidae e Dilleniidae (fitossociologia).

\section{Universidade de Brasília}

TÍTULO: Distribuição espacial de espécies perenes em uma mata de galeria inundável no Distrito Federal: florística e fitossociologia

AUTOR: Bruno Machado Teles Walter

DATA: Abril de 1995.

LOCAL: Universidade de Brasília - UnB

NÍVEL: Mestrado

BANCA EXAMINADORA: José Felipe Ribeiro (orientador) - UnB

Mundayatan Haridasan - UnB

Jeanine Maria Felfili-Fagg - UnB

Manoel Cláudio Silva Júnior - UnB

RESUMO - Este estudo foi desenvolvido na mata de galeria inundável do córrego da Onça, localizada na Fazenda Água Limpa (FAL, UnB), Brasília/DF. Teve por objetivo verificar a distribuição espacial de espécies perenes ao longo da mata, correlacionando-a com a topografia, o solo e a altura do lençol freático. Foram estabelecidas sistematicamente 200 parcelas de $10 \mathrm{~m}$ por $3 \mathrm{~m}$ paralelas ao córrego, sendo 60 parcelas na cabeceira, 60 na porção central da mata e 80 no trecho final. A área amostrada foi de 0,6 ha. $O$ diâmetro mínimo de caule adotado foi de $3 \mathrm{~cm}$ (diâmetro à altura do peito), incluindo não só árvores, mas também samambaias e cipós. Foram amostrados 2.640 indivíduos pertencentes a 49 famílias, 81 gêneros e 97 espécies. Na cabeceira foram amostradas 61 espécies entre os 561 indivíduos incluídos, sendo 26 espécies exclusivas deste trecho. Na porção central foram encontradas 60 espécies, em 886 indivíduos, sendo 10 exclusivas; e no trecho final, 53 espécies entre os 1.193 indivíduos amostrados, sendo 9 espécies exclusivas. Foi feito também o levantamento florístico das plantas vasculares que ocorrem nesta mata e os resultados apontam para a presença de 229 espécies em 89 familias. Verificaram-se mudanças florísticas significativas ao longo da mata, onde é baixa a similaridade entre trechos, apesar da alta diversidade nos três, e em consequuência, alta diversidade na mata. O número de espécies importantes é baixo e é alto o 